\title{
Scar endometriosis - a rare cause for a painful scar: A case report and review of the literature
}

\author{
Payman J Danielpour MD ${ }^{1}$, John C Layke DO ${ }^{1}$, Nicole Durie MD², Laurence T Glickman MD FRCSC FACS ${ }^{1,3}$
}

PJ Danielpour, JC Layke, N Durie, LT Glickman. Scar endometriosis a rare cause for a painful scar: A case report and review of the literature. Can J Plast Surg 2010;18(1):19-20.

Endometriosis is described as the presence of functioning endometrial tissue outside the uterine cavity. Scar endometriosis is a rare disease, and is difficult to diagnose. The symptoms are nonspecific, typically involving abdominal wall pain at the incision site at the time of menstruation. It commonly follows obstetrical and gynecological surgeries. The diagnosis is frequently made only after excision of the diseased tissue. A case report of a patient with a troublesome scar after a caesarian section is presented. Surgical excision led to the diagnosis of scar endometriosis. The pathogenesis, diagnosis and treatment of this somewhat rare condition are discussed.

Key Words: Cutaneous endometriosis; Endometriosis; Incisional endometriosis; Painful scar; Scar endometriosis

$\mathrm{F}$ ndometriosis is defined as the presence or growth of ectopic Eendometrial tissue (1). Affecting an estimated 89 million women of reproductive age worldwide, endometriosis occurs in $5 \%$ to $10 \%$ of all women, often resulting in debilitating pain and infertility. Although most frequently found in the pelvis, reports citing extrapelvic endometrial locations range from the lungs to the extremities (2). Incisional or scar endometriosis has also been described, however, with a much rarer incidence (fewer than $1 \%$ of affected patients) (1,3). This entity can result in unnecessary procedures, delayed or misdiagnosis, and can cause emotional and physical distress to the patient. The present study describes a case of scar endometriosis, and reviews the literature to elucidate physical signs and symptoms that may lead to earlier diagnosis and prompt treatment.

\section{CASE PRESENTATION}

A 26-year-old African-American woman was seen in consultation for a painful abdominal scar. She was an otherwise healthy woman with no significant medical history. Her surgical history included an uncomplicated caesarian section three years previously. She complained of increasing pain and tenderness at the Pfannenstiel incisional site, but did not report any cyclical pattern associated with these symptoms.

Physical examination revealed a well-healed caesarian scar, with a nonmobile, nodular, moderately pigmented area at its lateral border (Figure 1). Exquisite point tenderness to palpation over the nodular area was noted. A preliminary diagnosis of neuroma was entertained, and the patient was taken to the operating room for exploration of the abdominal wound and possible neuroma excision.

\section{L'endométriose cicatricielle, une rare cause de cicatrice douloureuse : Rapport de cas et analyse bibliographique}

\begin{abstract}
L'endométriose se décrit par la présence de tissu endométrial fonctionnel à l'extérieur de la cavité utérine. L'endométriose cicatricielle est un problème rare difficile à diagnostiquer. Les symptômes ne sont pas spécifiques et s'associent souvent à des douleurs de la paroi abdominale au foyer de l'incision lors des menstruations. Les manifestations suivent fréquemment une opération obstétricale et gynécologique. Le diagnostic est souvent posé après l'excision du tissu atteint. Le rapport de cas d'une patiente étant incommodée par une cicatrice après une césarienne est présenté. L'excision chirurgicale a permis de diagnostiquer une endométriose cicatricielle. La pathogenèse, le diagnostic et le traitement de ce problème plutôt rare sont exposés.
\end{abstract}

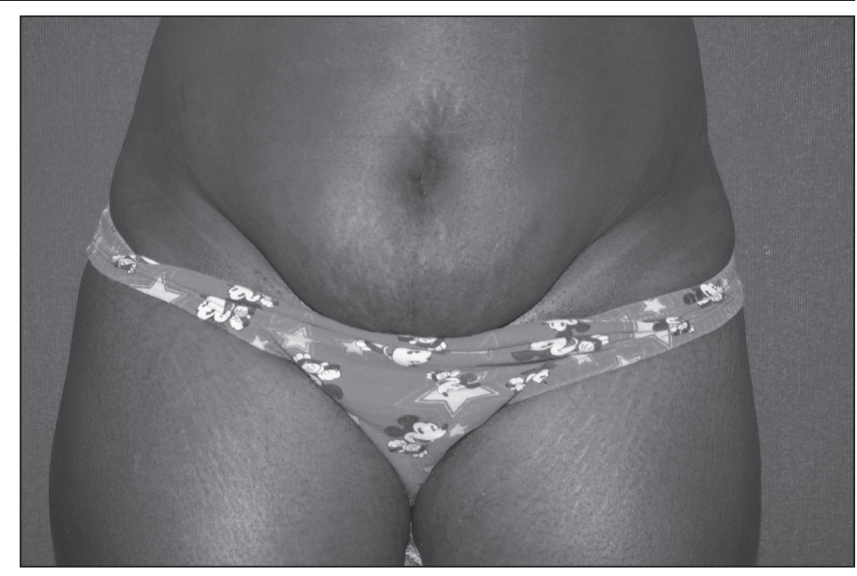

Figure 1) A well-healed caesarian scar, with a nonmobile, nodular, moderately pigmented area at its lateral border

Intraoperatively, extensive fibrosis of the scar to the fascia was noted. The scar was completely excised with the nodular portion, and the specimen was sent to the pathology department. The final report revealed "dermal fibrosis with endometriosis". The patient's postoperative course was uneventful, and her pain subsided.

\section{PATHOLOGY}

Endometriosis is defined by occurrence of endometrial-like epithelium and stroma outside the uterine cavity. This condition is commonly seen in females of reproductive age. Grossly, endometriosis may present as small, dark red, black or bluish

${ }^{1}$ Division of Plastic Surgery, Nassau University Medical Center, East Meadow; ${ }^{2}$ Department of Pathology, Winthrop University Hospital,

Mineola; ${ }^{3}$ Long Island Plastic Surgery Group, Garden City, New York, USA

Correspondence: Dr Laurence T Glickman, Long Island Plastic Surgery Group, 999 Franklin Avenue, Garden City, New York 11530, USA.

Telephone 516-742-3404, e-mail lglickman@lips.com 


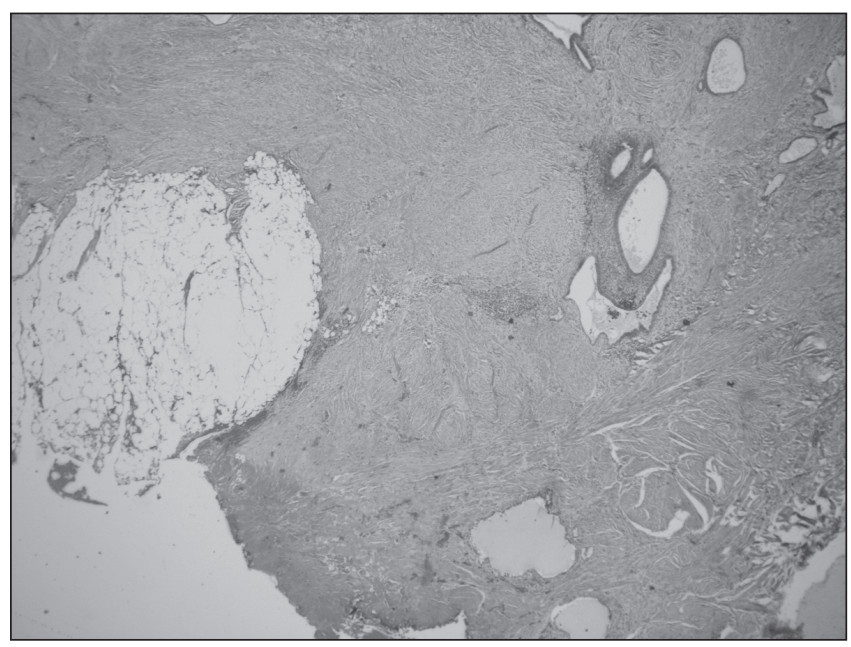

Figure 2) Hematoxylin and eosin photomicrograph showing scar tissue surrounding benign endometrial glands and stroma consistent with endometriosis (original magnification $\times 20$ )

cysts or nodules on the surface of peritoneal and pelvic organs. Histologically, endometriosis is characterized by the ectopic presence of endometrial-like glands, spindled endometrial stroma and hemosiderin deposition either within the macrophages or in the stroma (Figures 2 and 3). In many cases, this diagnostic triad is not present, or the glands and stroma may be obscured by hemorrhage, foamy cells and hemosiderin-laden macrophages. When this occurs, the diagnosis may be suggested but histological confirmation may not be possible.

\section{DISCUSSION}

Scar endometriosis is a rare entity reported in the gynecological literature, and presents in women who have undergone a previous abdominal or pelvic operation (4). The incidence has been estimated to be only $0.03 \%$ to $0.15 \%$ of all cases of endometriosis $(1,3)$. Many theories as to the cause of scar endometriosis have been postulated; however, the most generally accepted theory is the iatrogenic transplantation of endometrial implants to the wound edge during an abdominal or pelvic surgery $(1,3,5,6)$.

The diagnosis of scar endometriosis may be challenging. Cyclical changes in the intensity of pain and size of the endometrial implants during menstruation are usually characteristic of classical endometriosis. However, in the largest reported series (7) to date, only $20 \%$ of the patients exhibited these symptoms. Patients usually complain of tenderness to palpation and a raised, unsightly hypertrophic scar.

Management includes both surgical excision and hormonal suppression $(2,8)$. Oral contraceptives, progestational and androgenic agents have been tried. It is believed that hormonal suppression is only partially effective and surgical excision of the scar is the definitive treatment $(8,9)$.

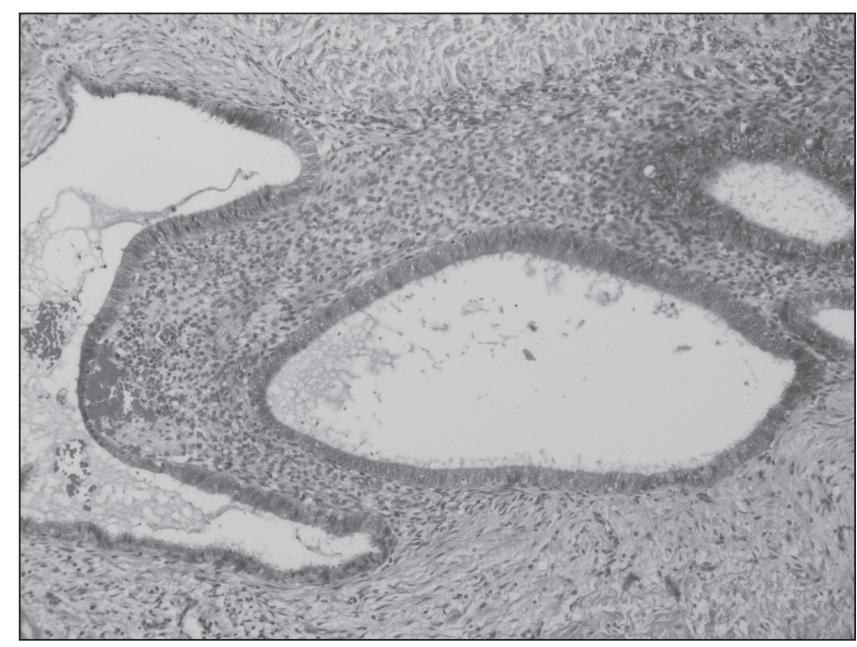

Figure 3) Hematoxylin and eosin photomicrograph showing benign endometrial glands and stroma surrounded by scar tissue consistent with endometriosis (original magnification $\times 100$ )

Scar endometriosis is a rare and often elusive diagnosis that can lead to both patient and physician frustration. One should maintain a high level of suspicion in any woman presenting with pain at an incisional site, most commonly following pelvic surgery. A thorough history and physical examination should always be performed, and every surgeon should consider this entity in their differential diagnosis.

ACKNOWLEDGEMENTS: The authors had no conflicts of interest to declare and maintained ethical adherence.

\section{REFERENCES}

1. Francica G, Giardiello C, Angelone G, Cristiano S, Finelli R, Tramontano G. Abdominal wall endometriosis near cesarean delivery scars. J Ultrasound Med 2003:22:1041-7.

2. Wolf G, Singh K. Cesarean scar endometriosis: A review. Obstet Gynecol Surv 1989:44:89-95.

3. Kaloo P, Reid G, Wong F. Caesarean section scar endometriosis: Two cases of recurrent disease and a literature review. Aust NZ J Obstet Gynaecol 2002;42:218-20.

4. Khoo JJ. Scar endometriosis presenting as an acute abdomen: A case report. Aust NZ Obstet Gynaecol 2003;43:164-5.

5. Tanos B, Anteby SO. Caesarean scar endometriosis. Int J Gynaecol Obstet 1994;47:163-6.

6. Douglas C, Rotimi O. Extragenital endometriosis: A clinicopathological review of Glasgow hospital with case illustrations. J Obstet Gynaecol 2004;24:804-8.

7. Ding CD, Hsu S. Scar endometriosis at the site of cesarean section. Taiwanese J Obstet Gynecol 2006;3:247-9.

8. Schoelefield HJ, Sajjad Y, Morgan PR. Cutaneous endometriosis and its association with caesarean section and gynaecological procedures. J Obstet Gynaecol 2002;22:553-4.

9. Wasfie T, Gomez E, Seon S, Zado B. Abdominal wall endometrioma after cesarean section: A preventable complication. Int Surg 2002;87:175-7. 